\title{
COMMUNITY INVOLVEMENT - IT CAN BE DONE
}

\section{A Project with the aged in Brakpan}

\author{
P.O. Sills \\ Chief Community Nurse, Brakpan Health Department
}

\section{THE BEGINNINGS}

In the course of their work the community nurses of Brakpan became aware of a large number of elderly people for whom there were few services available. Health Year (1979) gave rise to the idea of developing a project for the elderly in the community, with the prime objective of promoting their participation in and involvement with their own affairs.

It was hoped that such a project would lead to greater self-reliance on the part of the aged and that it would also be therapeutic for a number of the problems experienced by the elderly such as loneliness, feelings of uselessness and being unwanted, inactivity and a lack of creative opportunities. A clinic service, which would include health education, counselling, health screening and appropriate referral, was envisaged as the nucleus of the service with the possibility of other activities developing around this.

The Town Council was approached and permission was granted for the establishment of the service, provided that the cost to the Council would be minimal.

A public meeting for interested parties was advertised in the Municipal Newsletter and the local newspaper. About sixty senior citizens attended the first meeting. An outline of the proposed service and the role that the members could play in its implementation and development was presented to the group. A decision was taken by the elderly people that a weekly clinic service, at which tea would be served, was desirable.

Those present were invited to form an action group which would involve itself in the needs and problems of the aged. Twelve senior citizens volunteered for the task and they were met after the meeting by the community nurse, in her role as group leader. It was decided that red tape should be eliminated as far as possible and the minimum number of office-bearers, i.e. a group leader and a secretary/treasurer, were appointed. These were to be reelected annually.

It was further decided that membership to the group would be based on clinic attendance and that no membership fees would be required. For each new project a specific committee would be chosen which would disband once the objective had been achieved.

The first activity undertaken by this group was to meet the immediate needs of the clinic. These were the appointment of a voluntary clerk, raising finances to provide the refreshments and finding volunteers who would organise the teas. Volunteers were forthcoming and it was decided to collect small voluntary contributions at each meeting.

After some discussion and suggestions the group decided on a name: The Senior Citizens Action Group. The group would meet once a month.

\section{THE GROUP'S ACTIVITIES}

The first clinic session was well attended and the opportunity was used to introduce the action group members to the clinic attenders.

Action group meetings were held during clinic sessions. All those attending the clinic could thus take part in any project discussion.

The question of raising finances is of basic importance to any group. Some members suggested donations of handiwork which should be raffled and this was enthusiastically embarked upon. Equipment was purchased as the money became available. These small accomplishments resulted in excited teamwork, enthusiasm and a sense of cohesion in the group which gradually became ready for bigger challenges.

It was realised that an audiometer, to screen for deafness, which was very prevalent amongst the clients at the geriatric clinic, would be a valuable asset. This was discussed at an Action Group meeting and the group was challenged by the idea of providing the audiometer themselves. Within a year, this money was collected and an audiometer valued at $\mathrm{R} 648,00$ was purchased. The Town Council donated $\mathrm{R} 150,00$. The audiometer was presented to the mayor at a public function and the publicity given to the occasion added to the group's sense of pride and accomplishment.

The group's fund collecting activities was a matter of concern with regard to the legal implications of fund raising. The community nurse presented the problem to the group and it was decided to seek the advice of the Council for the Care of the Aged (Brakpan Branch) who subsequently agreed that the Action Group could become affiliated to them. The leader of the Action Group became a representative on their local committee.

Since there were many talented people amongst those who attended the clinic, it was decided to hold an exhibition of their work. The exhibition was extremely successful and has now become an annual event.

The Action Group's link with the clinic has been maintained and a bonus of this connection is that the Town Hall is made available free of charge to the group for various activities.

\section{EVALUATION OF THE SERVICE}

Initially much patience, encouragement, support and motivation were required, but each success on the part of the group members increased their confidence.

At times, the group wanted more involvement from the community nurse, for example to accompany them on an all-day outing. This type of dependence was however discouraged from the outset with the result that the group gained confidence in their ability to manage their own affairs.

The organising ability of the group has improved with experience although most of the responsibility still rests on the shoulders of the group leader and a small core of workers.

Jealousy within the group has occurred and action group members have sometimes expected preferential treatment at the clinic. These problems have been tactfully handled by the community nurse.

A team spirit has emerged between the community nurses and the elderly in the Brakpan community. Special efforts have been made to publicise the group's activities in order to gain recognition of the group by the wider community. For this purpose the community nurse has been prepared to address various meetings on the establishment, organisation, successes and failures of the project.

For the future, it would appear that the Action group would maintain close links with the clinic. The group is however almost autonomous. They undertake their own organisation and activities, with the community nurse acting for the most part in an advisory capacity only. 